RHS Revista Humanismo

RHS y sociedad
Editorial

doi: $10.22209 /$ rhs.v4n1a01

\title{
Pertinencia de la educación en ciencias e ingeniería en la coyuntura histórica actual
}

Globalización, tratados de libre comercio, intercambios económicos, transferencia tecnológica, internacionalización, y otras palabras y frases como estas son cada vez más comunes en nuestro vocabulario; todas reflejan que el mundo actual está interconectado y somos una parte de esa interconexión. Esto nos plantea grandes retos como país, ya que si queremos ser actores de peso en el mundo, debemos tener la capacidad de producir tecnología de calidad, la habilidad de transferir tecnologías extranjeras para acoplarlas a nuestras condiciones y la capacidad de conversar con los demás actores en el mundo sobre ciencia y tecnología, de forma que se puedan plantear proyectos de investigación y desarrollo de nuevas tecnologías, conservación, ecología, entre otros, para promover el crecimiento sostenible de nuestras regiones, regiones vistas como un conglomerado de países.

Si no aceptamos estos retos, estaremos subordinados a las condiciones que nos imponga el mundo, lo cual nos dejaría en gran desventaja, ya que muy pocos aspectos podríamos controlar como país. Estaríamos relegados a la tecnología que nos provea el resto del mundo, a los costos que nos quieran imponer y bajo las condiciones que nos indiquen. Seríamos un país del tercer mundo sin expectativas de ser un país emergente del llamado segundo mundo y mucho menos del primero.

Para enfrentar estos retos, la educación es la principal herramienta, en particular, la educación en ciencias exactas, naturales, ingeniería y en las áreas relacionadas con ellas. Un ejemplo claro de ello son los denominados tigres asiáticos. En los años cincuenta eran clasificados como países del tercer mundo, pobres, incluso más que el nuestro. Ahora son considerados países del segundo mundo, países con alto grado de desarrollo tecnológico, social y político; y lo consiguieron invirtiendo en educación. La apuesta fue enviar sus mejores estudiantes a realizar estudios de doctorado en ciencias, ingeniería y economía en las principales universidades del mundo y traerlos de nuevo a sus países a diseminar el conocimiento y mejorar su sistema educativo y con ello el técnico y tecnológico.

Dado que queremos ser un país con altos niveles de desarrollo sostenible, es necesario que nuestro sistema educativo esté alineado con los retos que se nos impone desde la economía globalizada; por lo tanto, debemos promover en nuestros estudiantes el amor por las ciencias, debemos procurar por enseñarla de forma tal que los conceptos básicos mínimos sean fácilmente asimilados, no solo porque sea nuestra profesión y día a día, sino porque es y será más aún en el futuro, fundamental para promover leyes, normas, tratados de comercio, pactos ambientales y demás prácticas de esta globalización, ya que el lenguaje de la industria calificada y de los grandes avances tecnológicos y sociales están ligados fuertemente al conocimiento científico básico y aplicado.

Un paso esencial para lograr esto es preparar nuestra sociedad en educación a nivel de posgrado, de forma tal que se obtenga un alto grado de especialización, un dominio del conocimiento específico por un alto número de habitantes de nuestra población, para que esta sea la semilla que disemine el conocimiento científico en la población y con ello se logre un grado alto de apropiación del lenguaje científico por parte del común de la población. De igual forma, esto sería un magnífico ejemplo para que las demás áreas del saber, ciencias sociales, políticas, artes, etc., promuevan movimientos similares en sus respectivos saberes, para así lograr ser una sociedad más educada en todos los ámbitos.

Wilber Silva López

Doctor en Ciencias Químicas Grupo de Energía y Termodinámica Universidad Pontificia Bolivariana 